Sharif University of Technology
Scientia Iranica
SCIENTIA
IRAN ICA
http://scientiairanica.sharif.edu

\title{
A new ground motion record selection procedure based on the effects of spectral share and period elongation
}

\author{
S. Ale Saheb Fosoul, H. Tajmir Riahi*, and N. Hatami Aloughareh \\ Department of Civil Engineering, University of Isfahan, Hezar Jarib St., Isfahan, Iran.
}

Received 6 August 2018; received in revised form 7 April 2019; accepted 21 December 2019

\author{
KEYWORDS \\ Record selection; \\ Spectral shape; \\ Period elongation; \\ Disaggregation \\ analysis; \\ Nonlinear dynamic \\ analysis; \\ Reinforced concrete \\ moment-resisting \\ frame.
}

\begin{abstract}
One of the most prevalent ground motion Intensity Measures (IMs) is the spectral acceleration at the fundamental period of a structure. Previous research has shown that vectorizing scalar IMs leads to a more reliable structural response, particularly in nonlinear regions and near collapse. Furthermore, the nonlinear behavior of ductile structures results in elongation of their "effective period". Therefore, this paper proposes a new approach to selecting ground motion records considering the effect of spectral shape and period elongation. This method contains two disaggregation analyses at the fundamental and elongated periods of the structure. Nonlinear dynamic analysis is conducted on a set of reinforced concrete moment-resisting frames designed based on ACI 318-05 as representatives of modern structures. Results show a considerable decrease in the median collapse prediction, margin against collapse, and dispersion of the structural response. The presented approach can ensure a better prediction of the vulnerability of structures to collapse.
\end{abstract}

(C) 2021 Sharif University of Technology. All rights reserved.

\section{Introduction}

One of the most challenging tasks in assessing the seismic performance of structures is selecting and scaling ground motion records for use in nonlinear dynamic analysis. The most common method for selecting records is the code-based method. Despite the simplicity and practicality of this method, it has considerable drawbacks $[1,2]$. There are different efforts to improve this method and increase its accuracy in estimating the seismic performance of structures. Some researchers try to improve it by using optimization

\footnotetext{
*. Corresponding author. Tel.: +983137935307 E-mail addresses: s.sahebfosoul@eng.ui.ac.ir (S. Ale Saheb Fosoul); tajmir@eng.ui.ac.ir (H. Tajmir Riahi); n.hatami@eng.ui.ac.ir (N. Hatami Aloughareh)
}

algorithms in the procedure [3-6] and others try to add some innovative complementary parameters to the selection process $[7,8]$. In order to amend the code-based method, it is important to understand the most significant properties of recorded ground motions, which are related to the structural response.

Intensity Measure (IM) is the parameter that quantifies the effect of a record on a structure. There is a variety of IMs which are commonly used for assessing the seismic performance of structures. Traditionally, peak ground acceleration of a record was one of the most frequent IMs among researchers. Recently, Shome et al. [9] showed that spectral responses (e.g., spectral acceleration at the first mode period of vibration $\left(S_{a}\left(T_{1}\right)\right)$ could predict the response of a structure in a more precise manner. However, there is still a significant variation between structural responses of a nonlinear multi-degree-of-freedom structure to the ground motion records with even similar values of 
$S_{a}\left(T_{1}\right)[10]$. Also, for the pulse-like records, it was observed that $S_{a}\left(T_{1}\right)$ was not a good predictor for the near-collapse response of nonlinear structures with elongated periods [11] or for a condition in which higher mode effects could be particularly significant $[12,13]$. Thus, many researchers have tried to solve this problem by selecting ground motion records such that their response spectra would match a target spectrum such as uniform hazard spectrum and, more recently, the conditional mean spectrum [14]. Target spectrum, which is obtained from Probabilistic Seismic Hazard Analysis (PSHA), makes a basis for the record selection procedure and the ground motion records must be selected with reasonable compatibility with this spectrum [15]. Recently, Kazantzi and Vamvatsikos [16] presented an average spectral acceleration, defined as the average of logarithmic values of spectral accelerations at different periods, which can predict the structural response with an acceptable level of dispersion. Similar average spectral accelerations are used in other studies for loss assessment of 3D buildings and development of conditional spectrum-based ground motion record selection methods $[17,18]$.

Another solution to this problem is developing efficient IMs that would lead to the introduction of vector-valued IMs [10]. These new IMs contain spectral acceleration as before as well as other complementary parameters such as magnitude, distance, or epsilon. Epsilon is defined as the number of logarithmic standard deviations between observed spectral value and mean $S_{a}$ prediction from a ground motion prediction attenuation model. Development of these approaches results in a significant decrease in the variability of predicted structural response [19-22]. This study uses a vector-valued IM including $S_{a}\left(T_{1}\right)$ and $\varepsilon$ as a superior predictor of structural response to better quantify the seismic performance and collapse potential of reinforced concrete moment-resisting frames. However, $\varepsilon$ is a period-dependent parameter with varying values at different periods [11]. Therefore, two questions arise: 1) what the appropriate value for epsilon is and 2) what period of vibration is a better quantifier of the structural response. The answer to the former question lies in the disaggregation analysis, which is explained in the following sections. Many researchers have tried to address the latter question, which leads to deep studies on the effect of period elongation, particularly on ductile modern structures. These investigations can be divided into two major categories: elongation of the vibration period based on the measured response of instrumented buildings during earthquakes [23-25] and experimental studies on the successive inelastic events of full-scale structural models [26-28]. It should be pointed out that the degree of period elongation estimated by numerical analysis is too controversial and differs from a factor of $1.50-1.70[29,30]$ up to
2.0-2.5 [31,32]. This alteration in the effective period of a structure during an earthquake results in changes in the dynamic behavior of the system, which implies the importance of the record selection procedure [33]. Prescription of most seismic codes on the necessity of spectral matching bandwidth as a function of the fundamental period declares this issue. This study follows the proposition of Haselton and Baker [34] which states that the optimal period of a structure extends approximately twice the fundamental period of the building.

\section{Spectral shape}

Spectral shape is one of the key characteristics of ground motion records. Baker and Cornell [35] carried out a series of deep studies on the spectral shape and showed that for rare ground motions in California (e.g., ground motions with a $2 \%$ probability of exceedance in 50 years), the shape of the response spectrum would be totally different from that of the code design spectrum or a uniform hazard spectrum. Figure 1 illustrates this difference by a comparison between the response spectrum of a single record of the Loma Prieta earthquake and the uniform hazard spectrum predicted by Boore attenuation prediction relations [36]. This ground motion record has been adopted from Saratoga station with NGA number of 803 and has a $2 \%$ probability of exceedance in 50 years within $1.0 \mathrm{sec}$. This figure declares that the ground motion response spectrum has some unusual peaks, especially between the periods of 0.6 and 1.8 seconds, and this makes it incompatible with Boore prediction in this range. These peaks occur around the period of $1 \mathrm{sec}$ in which it has $2 \%$ in 50-year intensity and the value of observed $S_{a}$ is much higher than the predicted one.

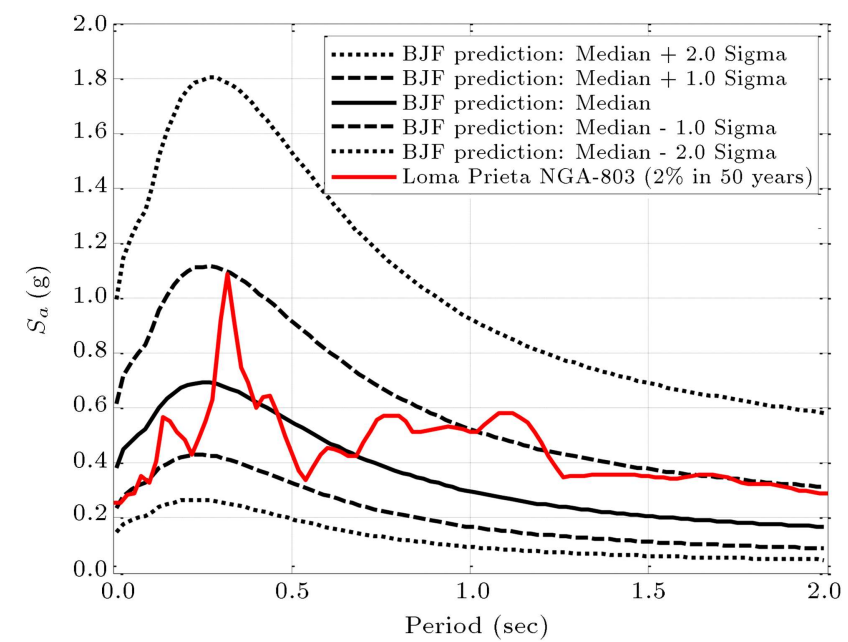

Figure 1. A comparison between the Loma Prieta (NGA-803) response spectrum and the intensity predicted by Boore [11]. 
This discrepancy between the observed and predicted spectral accelerations can be either positive or negative and it completely depends on the return period of ground motion and return period of the event that causes ground motions. A positive epsilon value corresponds to the greater value of the return period of ground motion (e.g., 2475 years for $2 \%$ in 50year motion) with respect to the return period of the event (e.g., typical event return periods are 150-500 years in California). On the other hand, a negative epsilon value stems from a shorter return period of the ground motion (e.g., 10 years for $50 \%$ in a 5-year motion) than the typical return period of the event (e.g. 150 to 500 years). Consequently, it is concluded that epsilon measure is dependent on both hazard level and site [37].

Recent research has shown that ignoring this peaked spectral shape leads to a significant bias in predicting the collapse potential of a structure, especially when the peaks occur around the fundamental period of the building, which is used in $S_{a}\left(T_{1}\right)$ for the procedure of scaling ground motion records [34,38]. Therefore, it is emphasized that considering epsilon measure in addition to spectral acceleration is necessary for a precise estimation of the structural performance. Epsilon is calculated using the following relation:

$$
\varepsilon=\frac{\ln \left(S_{a}\right)_{d a t a}-\ln \left(\mu_{S_{a}}\right)}{\sigma_{S_{a}}},
$$

where $\left(S_{a}\right)_{\text {data }}, \mu_{S_{a}}$, and $\sigma_{S_{a}}$ are spectral accelerations of each individual record, mean of the predicted logarithmic spectral acceleration, and standard deviation estimated by ground motion prediction equation, respectively [10]. In this study, a vector-valued IM including $S_{a}$ and $\varepsilon$ is considered and the AbrahamsonSilva attenuation relationship [39] is used for obtaining the noted predictive variables.

\section{Methodology}

This study introduces a new record selection approach that results in better quantification of the seismic performance of structures. In this method, ground motion records are selected based on their epsilon values in addition to their compatibility with the hazard level of interest. The innovation of this method lies in its ability to incorporate the effect of period elongation. It has been known that modern design codes permit structures to behave in a more ductile manner, causing them to experience a higher level of damage accumulation. This suggests that better quantification of nonlinear building responses to the ground motion records needs to use an appropriate $S_{a}\left(T_{I M}\right)$, where $T_{I M}$ is not necessarily $T_{1}$ but the elongated period. Therefore, considering the epsilon value in just one period may be somehow unconservative.
In this study, the mean fundamental period of four considered frames is $1 \mathrm{sec}$ and their corresponding elongated period is assumed $2 \mathrm{sec}$ based on the proposition of Haselton and Baker [34], which suggests the period elongation factor of 2.0 for ductile structures. Disaggregation analysis has been conducted for these periods to obtain the target epsilon values at three different hazard levels: $20 \%, 10 \%$, and $2 \%$ in 50 years. It should be noted that the effective period elongation of a structure during inelastic response is strongly dependent upon the post-linear behavior of the system and the degree of ductility demand. Then, two record selection methods are applied:

- Method 1. The common method in which a suite of 20 ground motion records is selected based on the compatibility of the suite's mean epsilon value (i.e., $1 \mathrm{sec}$ ) with the target epsilon value obtained from disaggregation analysis;

- Method 2. Another suite of 20 ground motion records is selected such that their epsilon values at both fundamental and elongated periods (i.e., 1 and $2 \mathrm{sec}$ ) match the target epsilon value obtained from disaggregation analysis.

This procedure was applied six times at three different hazard levels, resulting in three suites for each method. All the ground motion records were downloaded from PEER-NGA ground motion database [40].

\section{Archetype moment frames}

To obtain a proper estimation of structural collapse, precise modeling of structural components is required. In addition, a careful selection of ground motion records should be done. Therefore, a set of fourstory reinforced concrete moment-resisting frames is selected. These frames have three bays and represent mid-rise structures. They are designed based on ACI 318-05 [41] design code. Material nonlinearity is modeled using concentrated plastic hinges which consider strength and stiffness degradations. These hinges are located at the end of elastic elements for the beams and columns and behave based on the Ibarra model, which is implemented into OpenSees by Altoontash [42] and Ibarra and Krawinkler [43]. The frames have a mean fundamental period of $1 \mathrm{sec}$ and it is assumed that when the frames behave in a nonlinear region, their mean fundamental period will be 2 sec. Table 1 presents a brief description of the frames and more details can be found in Haselton's study [37]. OpenSees [44] is used for modeling all frames and Incremental Dynamic Analysis (IDA) is utilized to monitor the seismic performance of structures from the linear elastic region up to collapse [45]. 
Table 1. Design information of the archetype frames used in this study.

\begin{tabular}{cccccc}
\hline $\begin{array}{c}\text { Design } \\
\text { number }\end{array}$ & $\begin{array}{c}\text { Design ID } \\
\text { number in } \\
\text { Haselton's study }\end{array}$ & $\begin{array}{c}\text { Period } \\
(\mathbf{s e c})\end{array}$ & $\begin{array}{c}\text { No. of } \\
\text { stories }\end{array}$ & $\begin{array}{c}\text { Bay width } \\
(\mathbf{f t})\end{array}$ & $\begin{array}{c}\text { Lateral } \\
\text { load-bearing } \\
\text { system }\end{array}$ \\
\hline 1 & 1003 & 1.12 & & 20 & Perimeter \\
2 & 1008 & 0.94 & 4 & & Space \\
3 & 1009 & 1.16 & & 30 & Perimeter \\
4 & 1010 & 0.86 & & & Space \\
\hline
\end{tabular}

\section{Disaggregation analysis and record selection}

In this section, choosing an appropriate value for epsilon, which will be used in the record selection process, is discussed. Generally, disaggregation analysis is employed to understand the effects of different faults and probable events on the earthquake hazard in a specific region. This analysis utilizes Bayes' theorem to combine different seismic sources of a specific region to obtain their contribution at a specific hazard level $[15,46]$. Mean epsilon value is one of the outputs of this analysis. The United States Geology Survey (USGS) online tool is used in this study [47], which is based on McGuire's approach, for performing disaggregation analysis [37]. In this study, disaggregation analysis has been done for Los Angeles Bulk Mail site (Latitude/Longitude $=34.052^{\circ} /-118.244^{\circ}$ ) considering a mean shear wave velocity of $V_{s 30}=285$ $\mathrm{m} / \mathrm{s}$ [48]. 4D results are given in Figures 2-4. To study the effect of the spectral shape, disaggregation analyses have been done at three different hazard levels of $20 \%, 10 \%$, and $2 \%$ in 50 years and the obtained epsilon values are tabulated in Table 2 .

Individual response spectra and mean response spectrum of the selected ground motion records for $20 \%$ at a 50-year hazard level are given in Figure 5. This figure indicates that selecting accelerograms considering epsilon values at both fundamental and elongated periods makes the record suite somehow stronger at longer periods. This trend is similar for two other hazard levels, which are not presented here for brevity.

It should be pointed out that seismological investigations suggest that it is quite uncommon in the

Table 2. Obtained epsilon values from disaggregation analysis.

\begin{tabular}{ccc}
\hline \multirow{2}{*}{ Hazard level } & \multicolumn{2}{c}{ Epsilon } \\
\cline { 2 - 3 } & Period = 1 $\mathbf{~ s e c ~}$ & Period $=\mathbf{2}$ sec \\
\hline 224 years & 0.48 & 0.65 \\
475 years & 0.67 & 0.90 \\
2475 years & 1.18 & 1.37 \\
\hline
\end{tabular}

response spectrum of a single ground motion record to have peaks at two periods simultaneously. However, response spectra of the ground motion records of some earthquakes such as Chi-Chi or Northridge show that large epsilon values at two periods are attainable in such ground motion records. Figure 6 shows the response spectra of three ground motion records from Northridge, Kobe, and Loma Prieta earthquakes. It is shown that some high amplitude ground motion records have peaks both at fundamental and elongated periods. Moreover, a recent study has shown that $\varepsilon\left(T_{1}\right)$ and $\varepsilon\left(T_{2}\right)$ are highly correlated, particularly when the difference between the two periods is negligible. In this study, where two periods are 1 and 2 sec and the correlation of $\varepsilon$-index of these two periods is in the range of $0.7-0.8$ for different earthquake source zones [49].

The IDA is conducted by utilizing ground motion records selected based on the proposed approach. It is of high importance to know that scaling ground motion records will not cause any differences in the measure of epsilon as it is the indicator of spectral shape [14]. It should be noted that although scaling ground motion records in IDA is unrealistic, this method is used in this study to compare the effects of ground motion record selection methods on the collapse prediction of structures.

\section{Effect of the proposed record selection procedure on dispersion of seismic response of archetypes}

Notwithstanding the simplicity of using a scalar IM, a vector-valued IM can increase the accuracy of collapse prediction [49]. In addition, authors in this reference stated that neglecting the effect of spectral shape would result in overestimation of the demand on the structure. Therefore, the proposed record selection procedure tries to increase the precision of estimating a seismic structural response by considering the spectral shape in two periods. Hence, IDA has been performed six times for each model (three times corresponding to three hazard levels for Methods 1 and 2) using the 


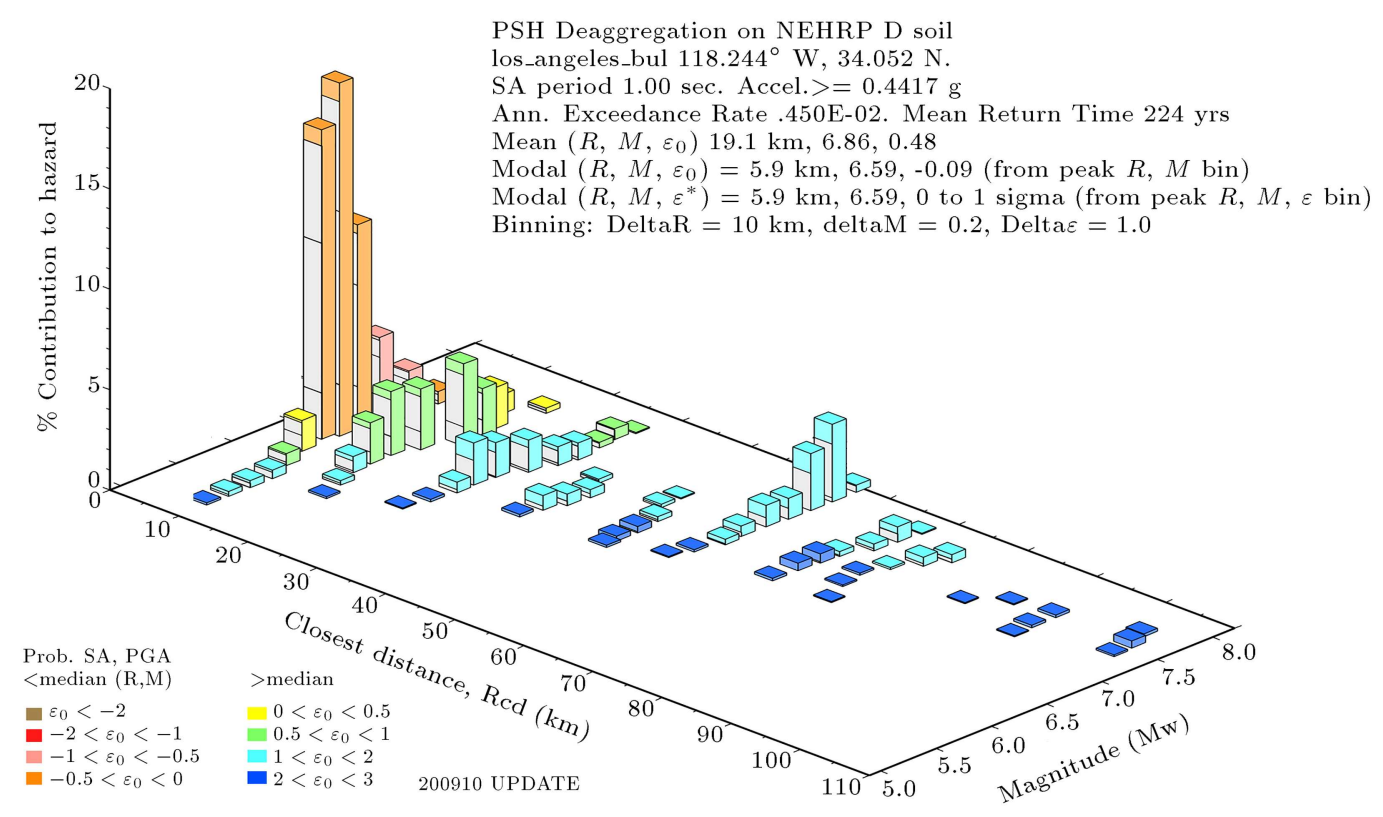

GMT 2013 Jun 4 07:34:49 Distance (R), magnitude (M), epsilon (E0,E) deaggregation for a site on soil with average vs $=285 \mathrm{~m} / \mathrm{s}$ top $30 \mathrm{~m}$. USGS CGHT PSHA2008 UPDATE Bins with It $0.05 \%$ contrib. omitted

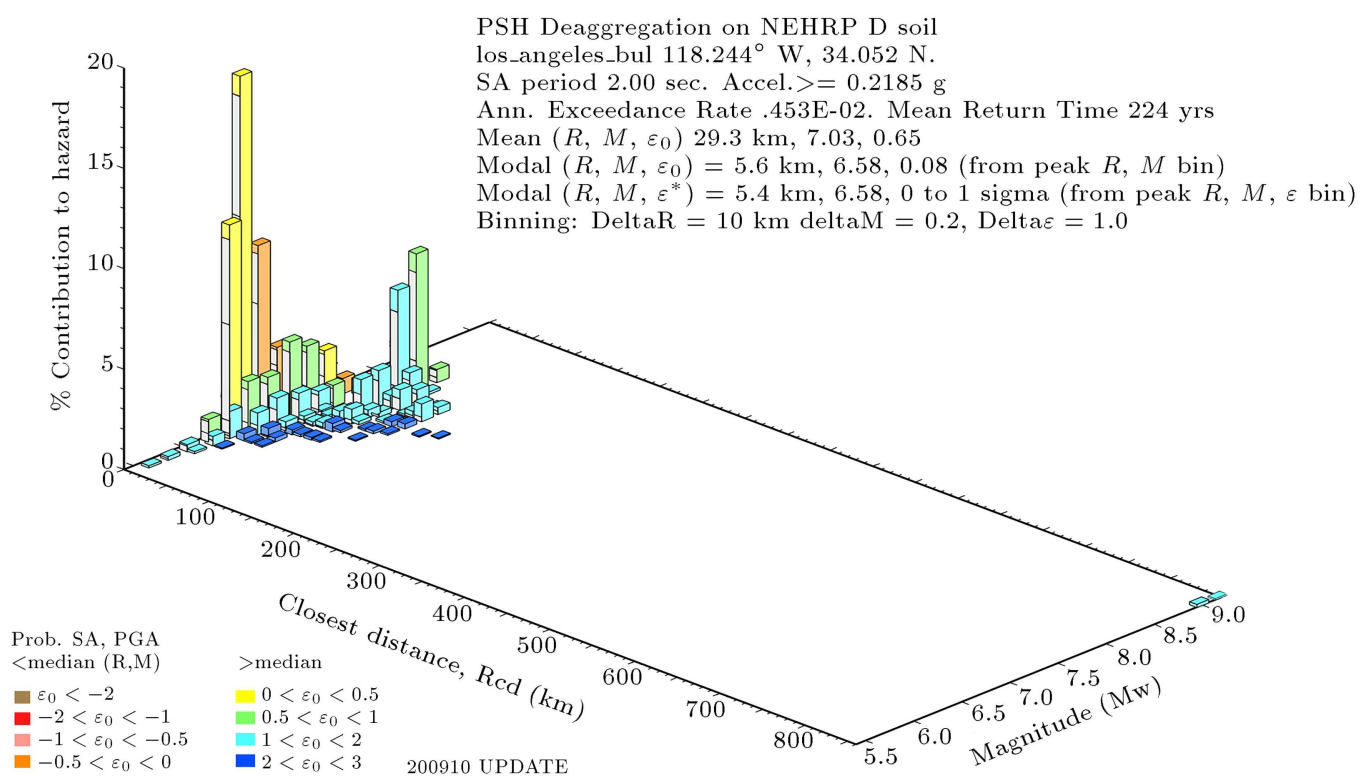

GMT 2013 Jun 4 07:50:54 Distance (R), magnitude (M), epsilon (E0,E) deaggregation for a site on soil with average vs $=285 \mathrm{~m} / \mathrm{s}$ top $30 \mathrm{~m}$. USGS CGHT PSHA2008 UPDATE Bins with It $0.05 \%$ contrib. omitted

Figure 2. Disaggregation analysis for $20 \%$ at a 50 -year hazard level: (a) Period $=1 \mathrm{sec}$ and (b) period $=2 \mathrm{sec}$.

ground motion record suites that have been selected based on compatibility of their epsilon values at $S_{a}\left(T_{1}\right)$ with that obtained from disaggregation analysis.

One of the key advantages of selecting ground motion records based on the proposed criterion is decreasing the variability of structural response. Figure 7 shows the median as well as $16 \%$ and $84 \%$ fractiles. It is shown that selecting ground motion records based on compatibility of epsilon values at both periods of 1 and 2 sec can effectively lessen the variability of structural response. Consequently, the collapse potential can be predicted by a higher level of confidence.

This comparison is made for other three frames; yet, only the results of frame 1003 are depicted here for brevity. However, the comprehensive results tabulated in Table 3 clearly show that the proposed procedure 


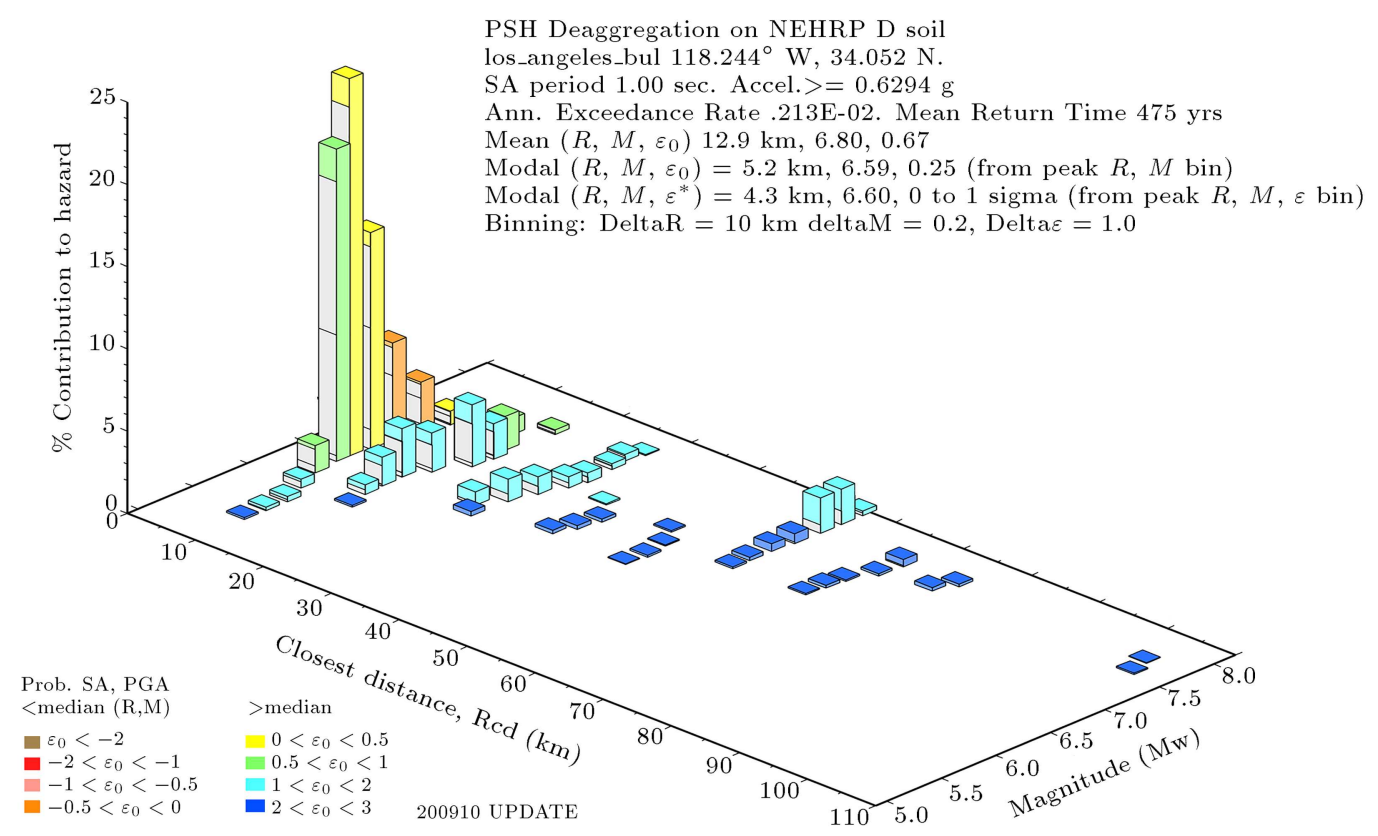

GMT 2013 Jun 4 07:34:16 Distance (R), magnitude (M), epsilon (E0,E) deaggregation for a site on soil with average $v s=285 \mathrm{~m} / \mathrm{s}$ top $30 \mathrm{~m}$. USGS CGHT PSHA2008 UPDATE Bins with It $0.05 \%$ contrib. omitted

(a)

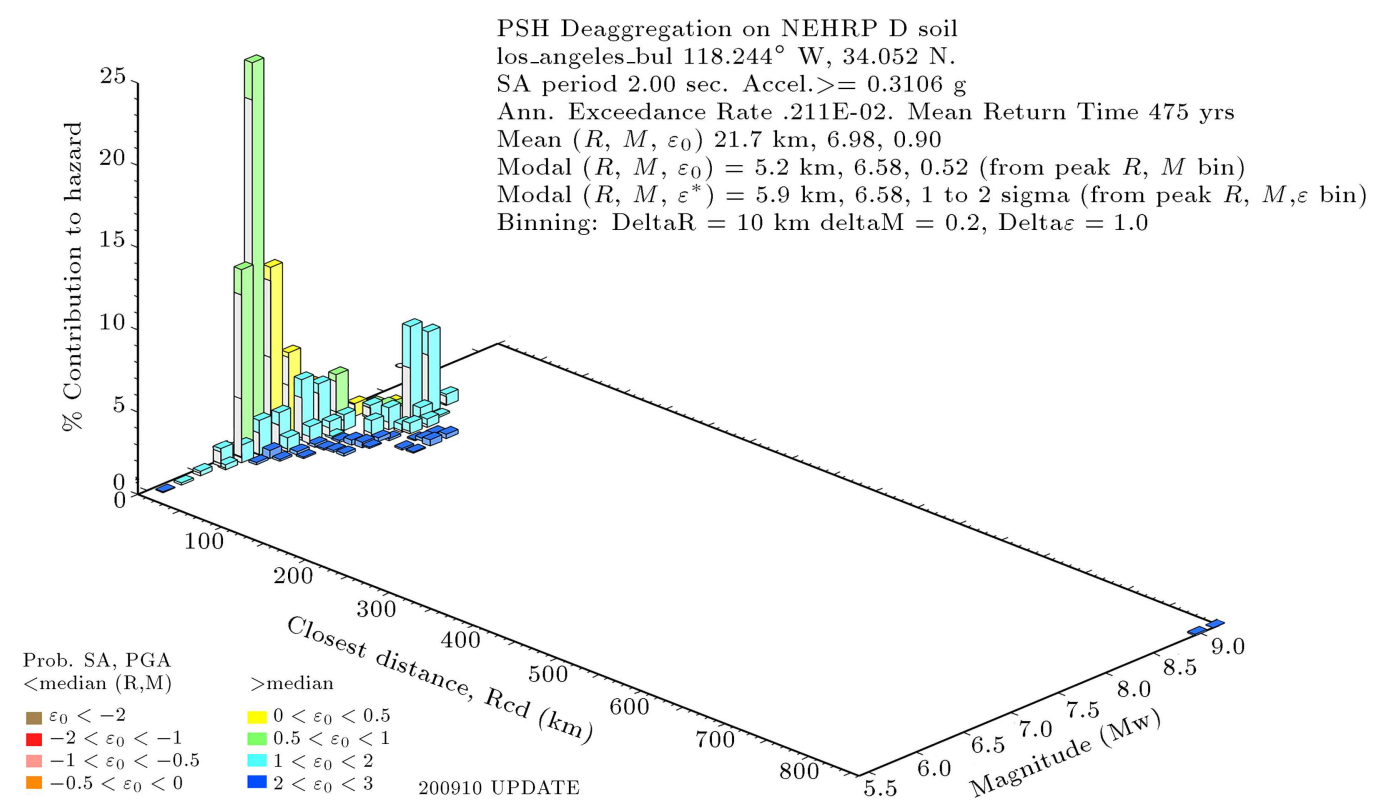

GMT 2013 Jun 4 07:50:26 Distance (R), magnitude (M), epsilon (E0,E) deaggregation for a site on soil with average vs $=285 \mathrm{~m} / \mathrm{s}$ top $30 \mathrm{~m}$. USGS CGHT PSHA2008 UPDATE Bins with It $0.05 \%$ contrib. omitted

(b)

Figure 3. Disaggregation analysis for $10 \%$ at a 50 -year hazard level: (a) Period $=1$ sec and (b) period $=2$ sec.

reduces the variability of structural response by $6 \%$ to $45 \%$ for all the frames. The discrepancy in the variability of structural response is calculated as the difference in the dispersion of $\left(S_{a}\right)_{\text {Collapse }}$ of the 16th and 84th fractiles of the IDA curves in Figure 7 for the two aforementioned record suites. Surprisingly, the reduction in the dispersion of the structural response is lower for events with a higher probability of occurrence (e.g., events with a 224-year return period) in perimeter frames. On the contrary, the structural response of space frames demonstrates a higher decrease in dispersion for rare earthquakes. 


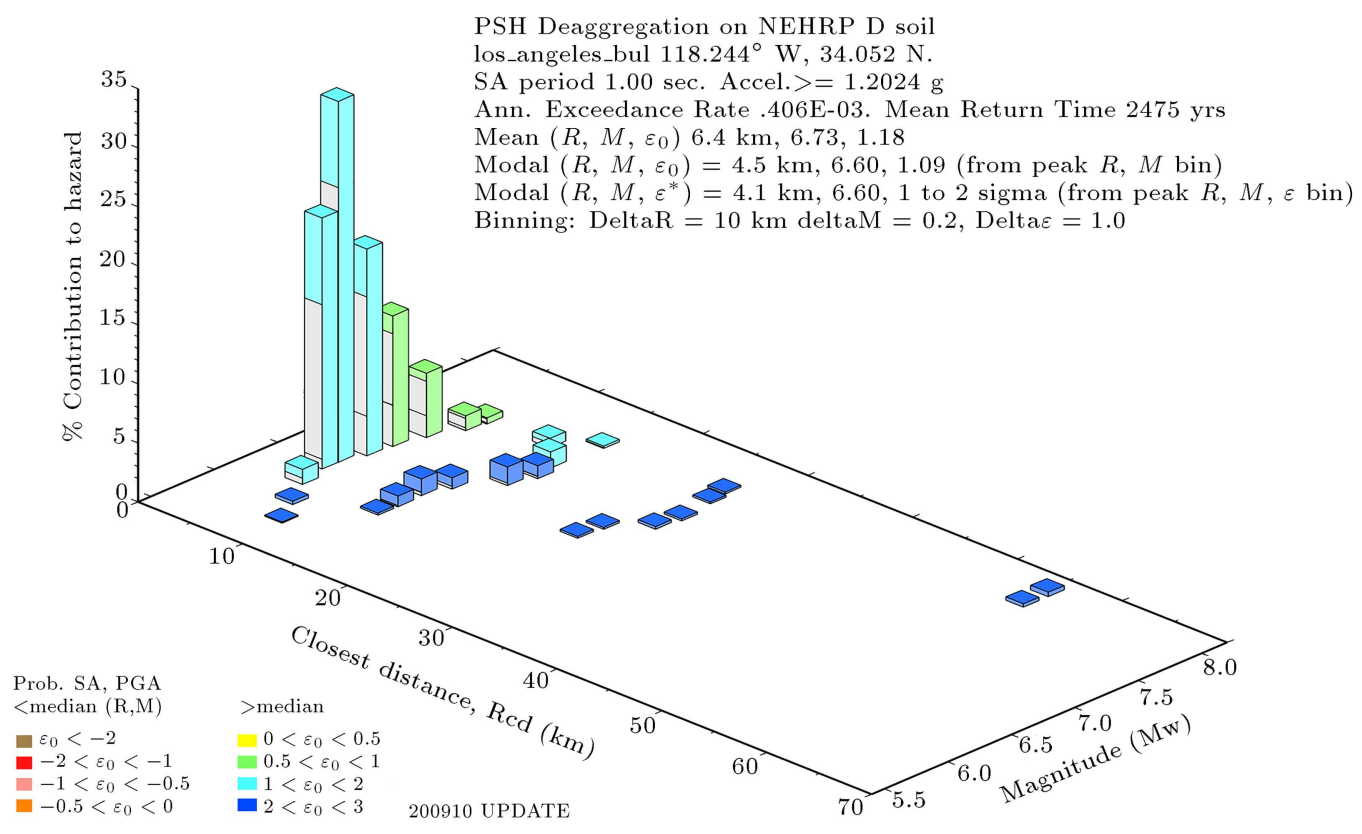

GMT 2013 Jun 4 07:04:26 Distance (R), magnitude (M), epsilon (E0,E) deaggregation for a site on soil with average vs $=285 \mathrm{~m} / \mathrm{s}$ top $30 \mathrm{~m}$. USGS CGHT PSHA2008 UPDATE Bins with It $0.05 \%$ contrib. omitted

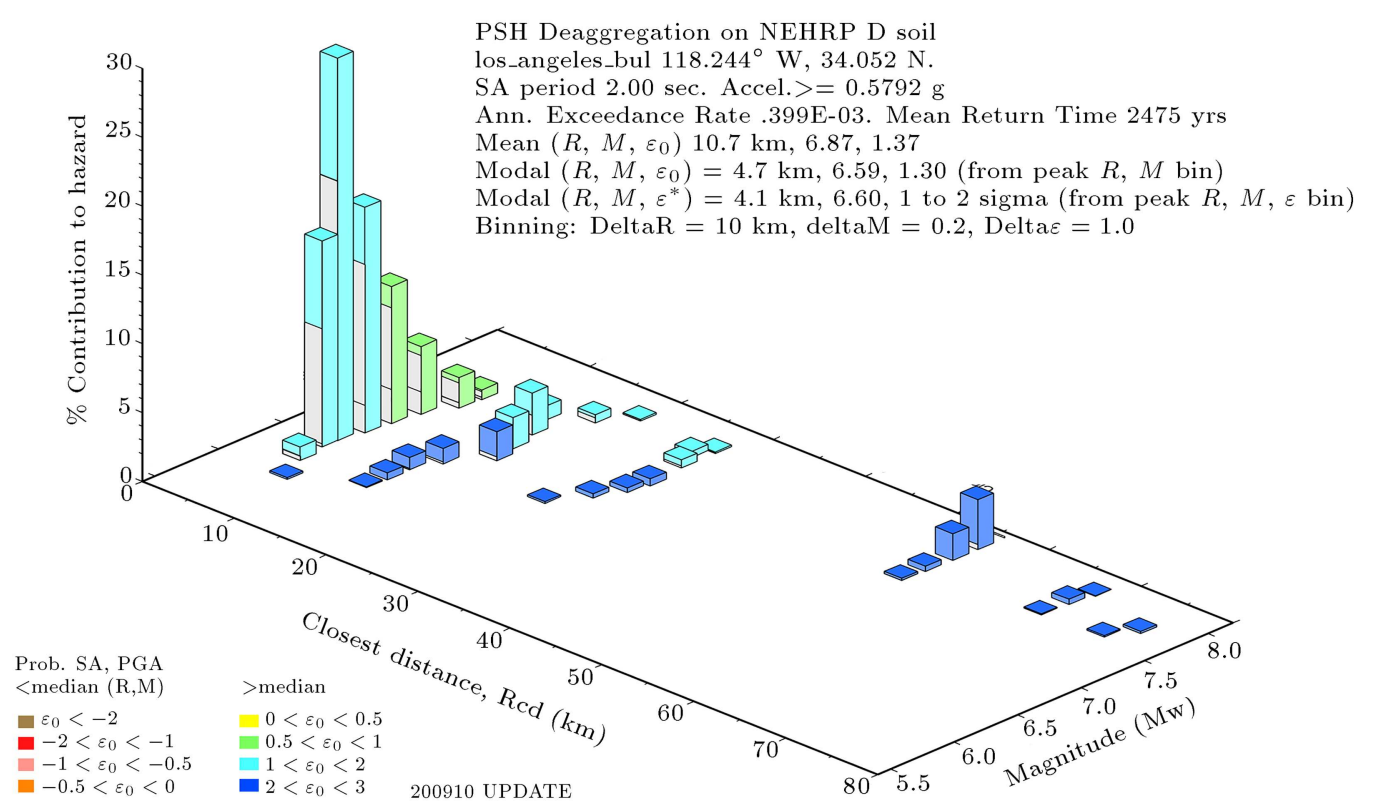

GMT 2013 Jun 4 07:49:45 Distance (R), magnitude (M), epsilon (E0,E) deaggregation for a site on soil with average vs $=285 \mathrm{~m} / \mathrm{s}$ top $30 \mathrm{~m}$. USGS CGHT PSHA2008 UPDATE Bins with It $0.05 \%$ contrib. omitted

Figure 4. Disaggregation analysis for $2 \%$ at a 50 -year hazard level: (a) Period $=1$ sec and (b) period $=2 \mathrm{sec}$.

\section{Seismic performance of archetypes under selected ground motion records}

Following the use of the selection and assessment method previously described, the performance of the introduced frames is discussed in this section. Figures 8-11 present the overall results in terms of (a) the median of IDA curves and (b) the collapse capacity cumulative distribution function for the common and proposed record selection methods. In drawing the collapse fragility curves, it is assumed that $\left(S_{a}\right)_{\text {Collapse }}$ has a lognormal distribution.

Part (a) of Figures 8-11 demonstrates the significant effect of the design concept on the seismic behavior and collapse safety of the structures. As anticipated, space frames outperformed perimeter frames. This behavior is associated with the dominance of lateral and gravity loads in the design. In other words, 


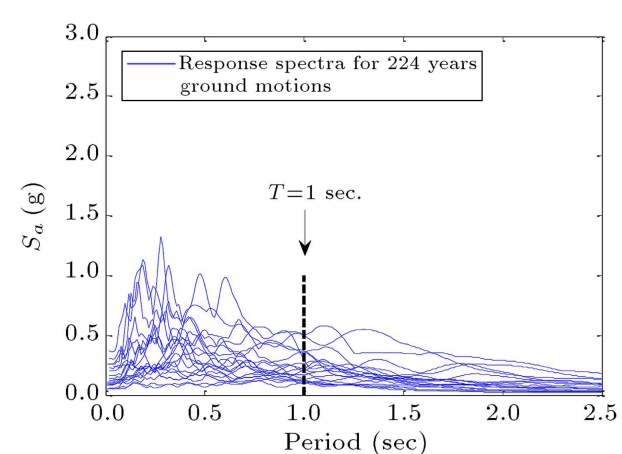

(a)

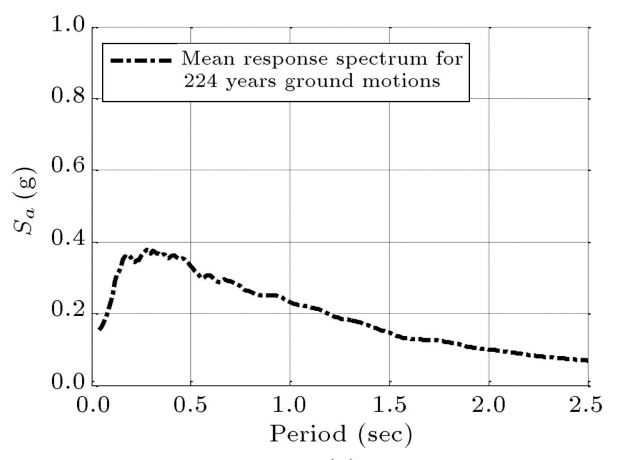

(c)

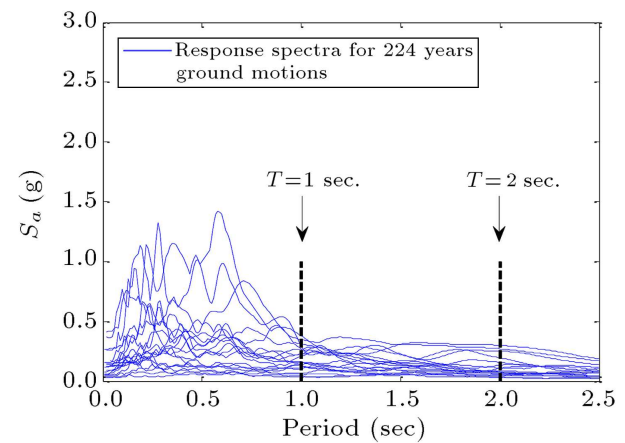

(b)

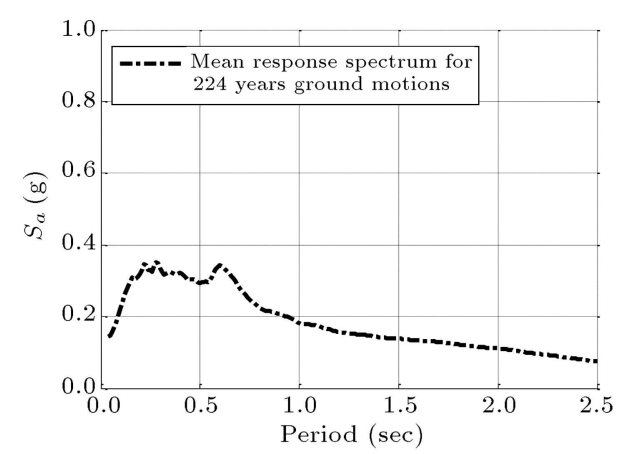

(d)

Figure 5. Response spectra of selected accelerograms based on (a) fundamental period, (b) fundamental and elongated periods, and corresponding mean response spectrum, (c) and (d) for 20\% at a 50-year hazard level.

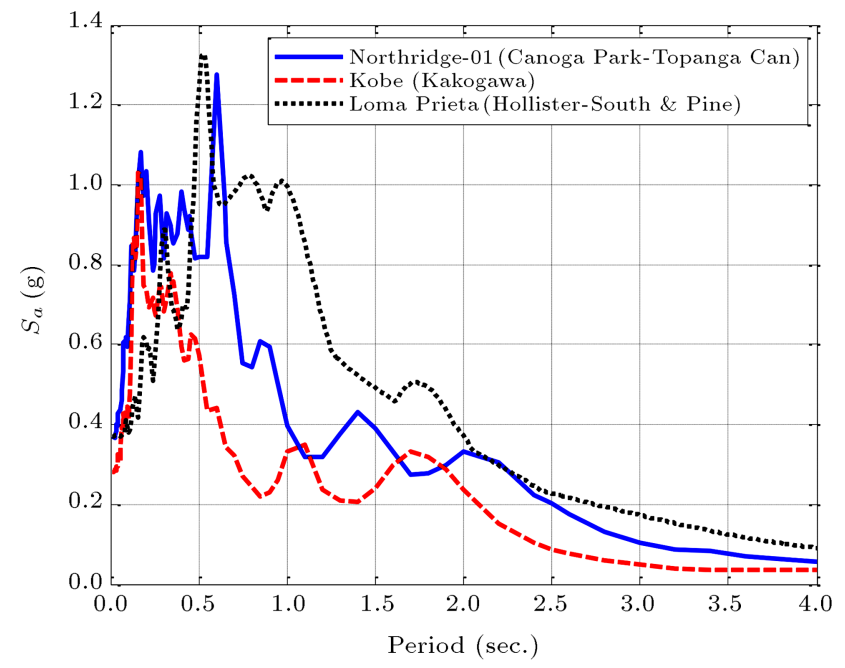

Figure 6. Response spectra of Northridge-Canoga Park, Kobe-Kakogawa, and Loma Prieta-Hollister records.

the tributary masses of perimeter frames are 3 to 5 times larger than those of space frames, making them experience larger P-Delta effects. Figures 8-11 confirm the appropriate behavior of space frames at all three hazard levels and it is consistent with the findings of Haselton et al. [50]. It should be noted that the structural responses to the ground motion records selected based on the proposed record selection method follow a similar trend. Moreover, the figures show that considering the extended period results in a conservative structural response in the nonlinear precollapse region. For example, the maximum drift of a structure subjected to a record suite selected based on the fundamental period is about 0.025 in $S_{a}=0.765$ ( $2 \%$ at a 50 -year $S_{a}$ level), where the structure collapses entirely under the record suite selected based on both fundamental and elongated periods.

The median collapse capacities predicted using the records based on an elongated period are smaller than those predicted using a common method of practice. These differences are in the range of $26-34 \%$, $27-31 \%$, and $19-28 \%$ for $2 \%, 10 \%$, and $20 \%$ at $50-$ year hazard levels. These results are in accordance with the research of Haselton and Baker [34] which predicted this difference to be in the range of $65 \%$. Consequently, the collapse margins of the structures are lower regarding the proposed approach. The collapse margins considering the elongated period are about 0.7 times lower than the margins predicted by the common selection method which has a comparable resemblance to the findings of Haselton and Baker [34]. Surprisingly, this research indicates that the collapse capacity prediction is less sensitive to the corresponding hazard level when the period elongation effect is considered.

Another interesting parameter is the dispersion of the structural response. Results indicate that there is no regular trend in the value of dispersion. For example, considering the effect of period elongation reduces the dispersion of the structural response of 


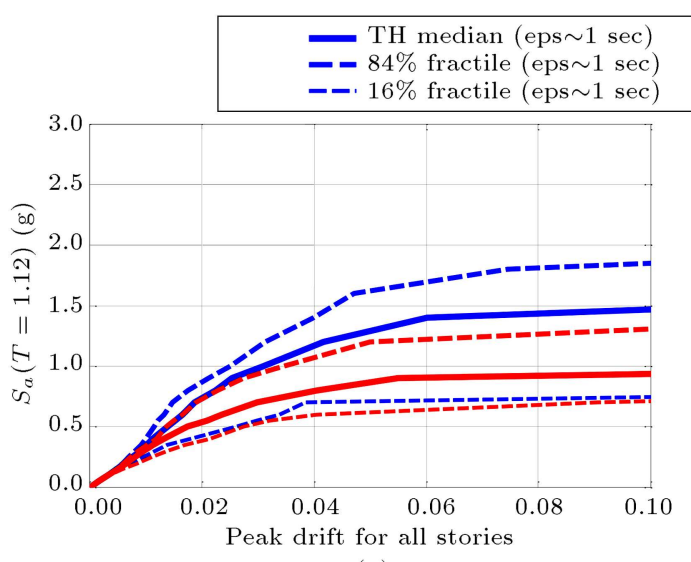

(a)

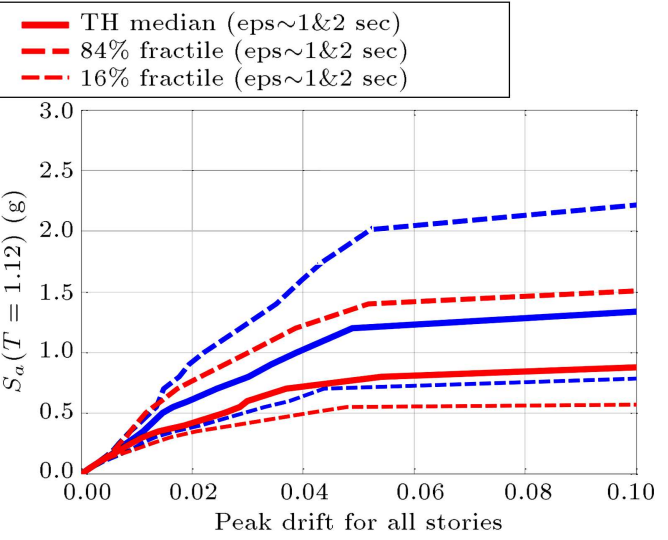

(b)

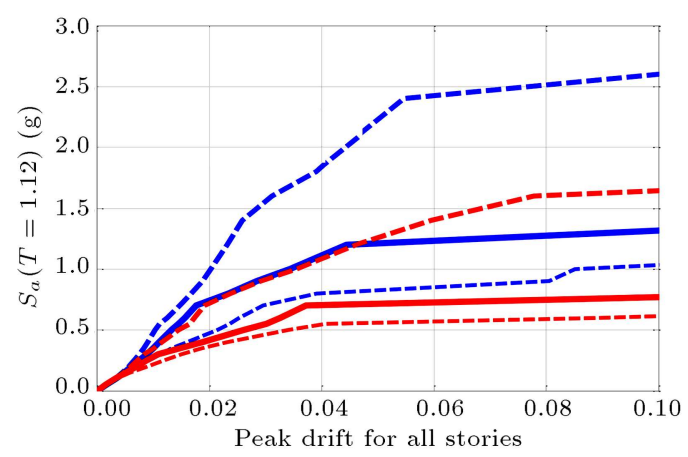

(c)

Figure 7. Median of the structural response at hazard levels of (a) 224 years, (b) 475 years, and (c) 2475 years based on both methods of considering epsilon values in periods 1 and $1 \& 2 \mathrm{sec}$ for frame 1003 .

Table 3. Comparison between the structural responses obtained from the Incremental Dynamic Analysis (IDA) using the common and those from the proposed methods.

\begin{tabular}{|c|c|c|c|c|c|c|c|}
\hline \multicolumn{2}{|c|}{$\begin{array}{c}\text { Return period } \\
\text { (years) }\end{array}$} & \multicolumn{2}{|c|}{224} & \multicolumn{2}{|c|}{475} & \multicolumn{2}{|c|}{2475} \\
\hline Frame no. & $\left(S_{a}\right)_{\text {Collapse }}$ & $\begin{array}{c}\varepsilon \sim 1 \\
\sec \end{array}$ & $\begin{array}{c}\varepsilon \sim 1 \& 2 \\
\sec \end{array}$ & $\begin{array}{c}\varepsilon \sim 1 \\
\text { sec }\end{array}$ & $\begin{array}{c}\varepsilon \sim 1 \& 2 \\
\text { sec }\end{array}$ & $\begin{array}{c}\varepsilon \sim 1 \\
\text { sec }\end{array}$ & $\begin{array}{c}\varepsilon \sim 1 \& 2 \\
\text { sec }\end{array}$ \\
\hline \multirow{3}{*}{1003 (perimeter) } & 16th fractile & 0.93 & 0.76 & 0.93 & 0.67 & 0.99 & 0.70 \\
\hline & 84 th fractile & 2.07 & 1.39 & 2.24 & 1.64 & 2.44 & 1.51 \\
\hline & Discrepancy (\%) & \multicolumn{2}{|c|}{-44.7} & \multicolumn{2}{|c|}{-26.0} & \multicolumn{2}{|c|}{-44.1} \\
\hline \multirow{3}{*}{1008 (space) } & 16th fractile & 1.17 & 0.85 & 1.49 & 0.96 & 1.19 & 0.93 \\
\hline & 84th fractile & 2.09 & 1.71 & 2.78 & 2.06 & 2.79 & 1.87 \\
\hline & Discrepancy (\%) & \multicolumn{2}{|c|}{-6.5} & \multicolumn{2}{|c|}{-14.7} & \multicolumn{2}{|c|}{-41.3} \\
\hline \multirow{3}{*}{1009 (perimeter) } & 16th fractile & 1.00 & 0.77 & 0.99 & 0.72 & 1.05 & 0.73 \\
\hline & 84 th fractile & 2.26 & 1.51 & 2.62 & 1.96 & 2.18 & 1.72 \\
\hline & Discrepancy (\%) & \multicolumn{2}{|c|}{-41.3} & \multicolumn{2}{|c|}{-23.9} & \multicolumn{2}{|c|}{-12.4} \\
\hline \multirow{3}{*}{1010 (space) } & 16th fractile & 1.59 & 1.23 & 1.96 & 1.39 & 1.98 & 1.36 \\
\hline & 84 th fractile & 3.10 & 2.59 & 4.01 & 2.94 & 3.53 & 2.56 \\
\hline & Discrepancy (\%) & \multicolumn{2}{|c|}{-9.9} & \multicolumn{2}{|c|}{-24.4} & \multicolumn{2}{|c|}{-22.6} \\
\hline
\end{tabular}




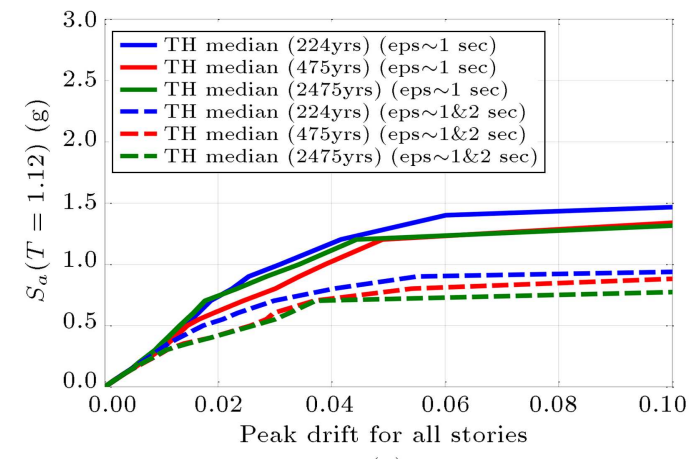

(a)

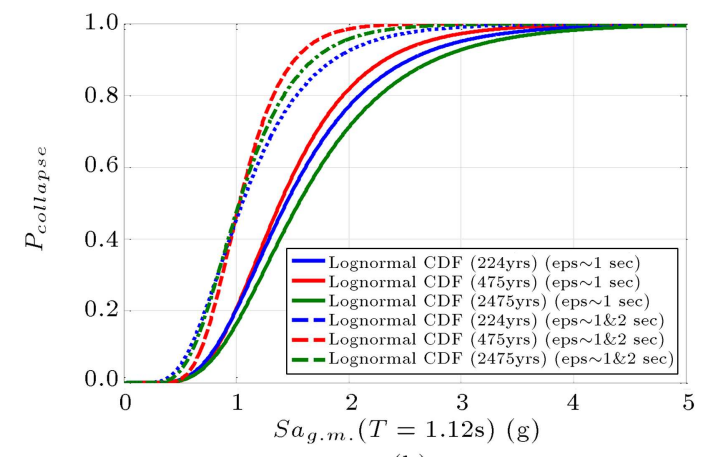

(b)

Figure 8. (a) Median of IDA curves and (b) collapse fragility curves at different hazard levels for Method 1 (solid line) and Method 2 (dashed line) for frame 1003.

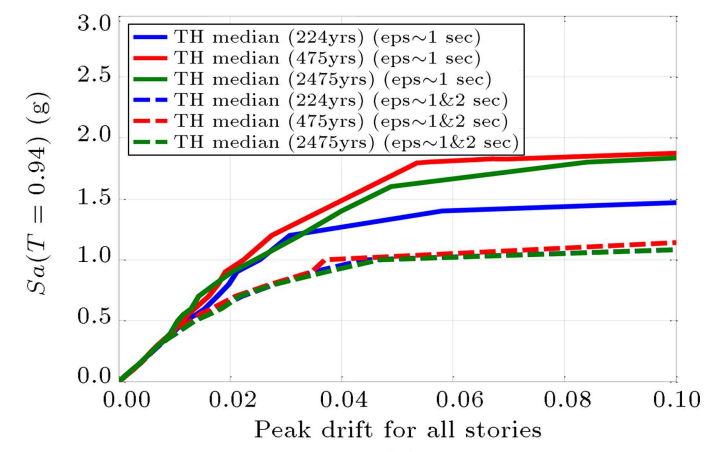

(a)

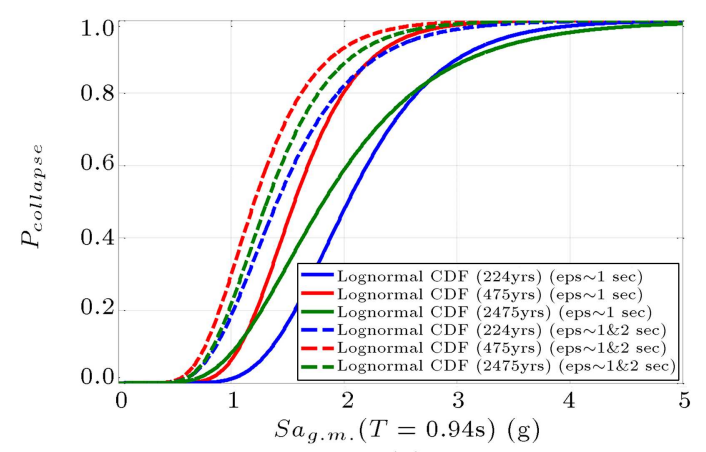

(b)

Figure 9. (a) Median of IDA curves and (b) collapse fragility curves at different hazard levels for Method 1 (solid line) and Method 2 (dashed line) for frame 1008.

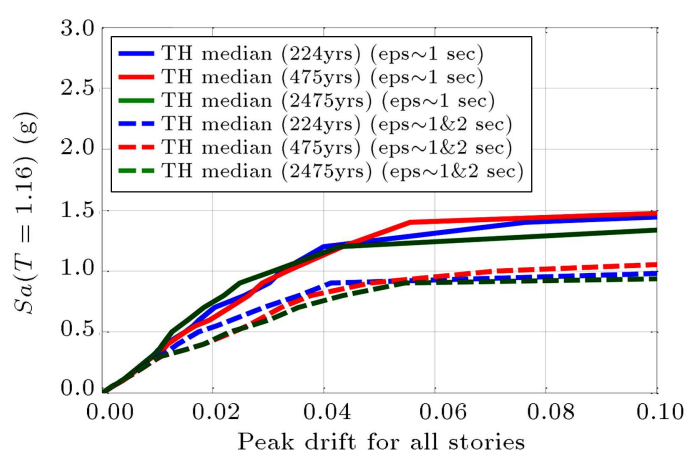

(a)

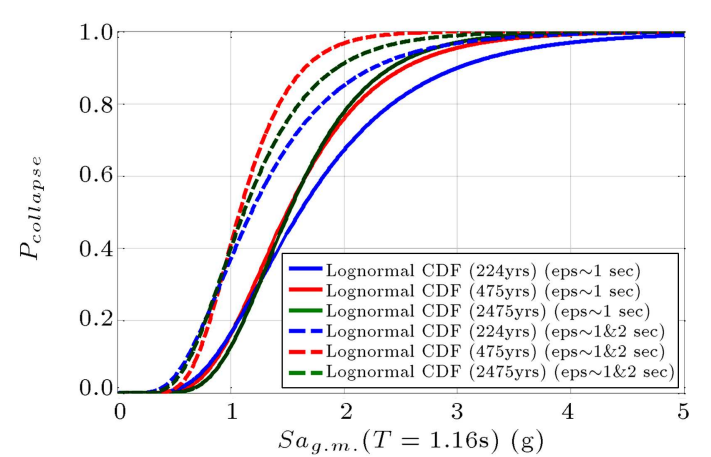

(b)

Figure 10. (a) Median of IDA curves and (b) collapse fragility curves at different hazard levels for Method 1 (solid line) and Method 2 (dashed line) for frame 1009.

frame 1008 by a factor of 0.8 for the 2475 -year motions where it is increased by the factor of 1.23 for the $475-$ year motions. Haselton and Baker [34] pointed to this irregularity over a range of periods.

Collapse safety can be expressed in terms of probability of collapse conditioned on a level of ground motion or a tolerable Mean Annual Frequency (MAF) of collapse. Both of these concepts adhere to two relations: 1) the relation of the ground motion IM and the probability of collapse (fragility curve), and 2) the relation of seismic hazard and the same ground motion IM (hazard curve) [51].
For this purpose, the probability of collapse at three hazard levels is calculated. It is shown that the probability of collapse is highly dependent on the loadbearing system. On the other hand, the proposed approach has a significant effect on the probability of collapse such that it increases this probability by factors up to 83. However, it is not a real value because it is associated with the tails of fragility curves where the values of parameters are so sensitive.

To complete this probabilistic assessment, the MAF of collapse $\left(\lambda_{\text {collapse }}\right)$ is calculated. It is done by integrating the conditional probabilities of collapse 


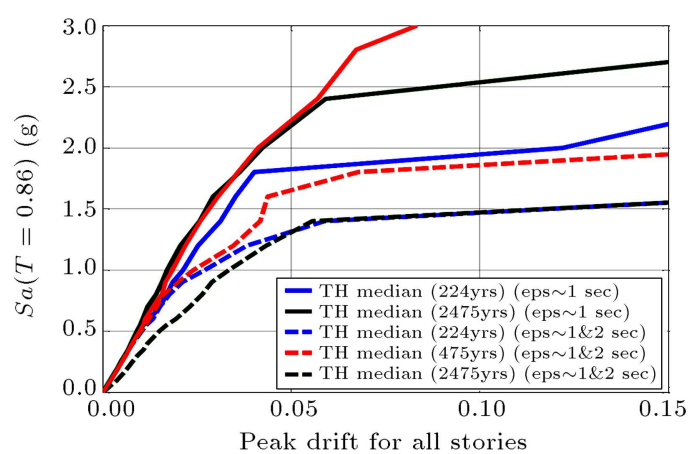

(a)

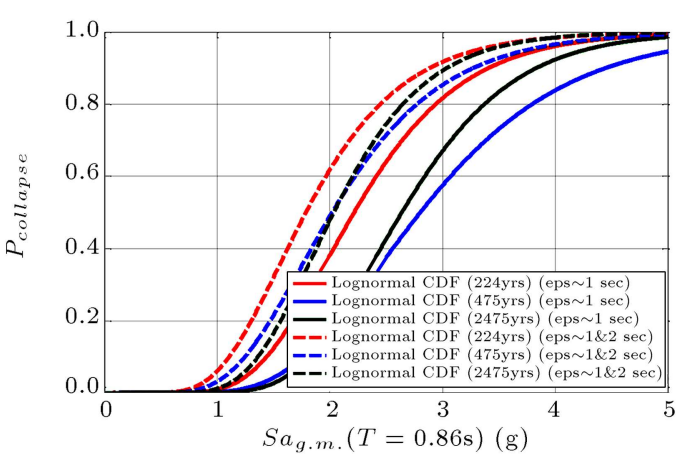

(b)

Figure 11. (a) Median of IDA curves and (b) collapse fragility curves at different hazard levels for Method 1 (solid line) and Method 2 (dashed line) for frame 1010.

Table 4. Collapse predictions for different design systems for $2 \%$ at a 50 -year hazard level including results for both record selection methods.

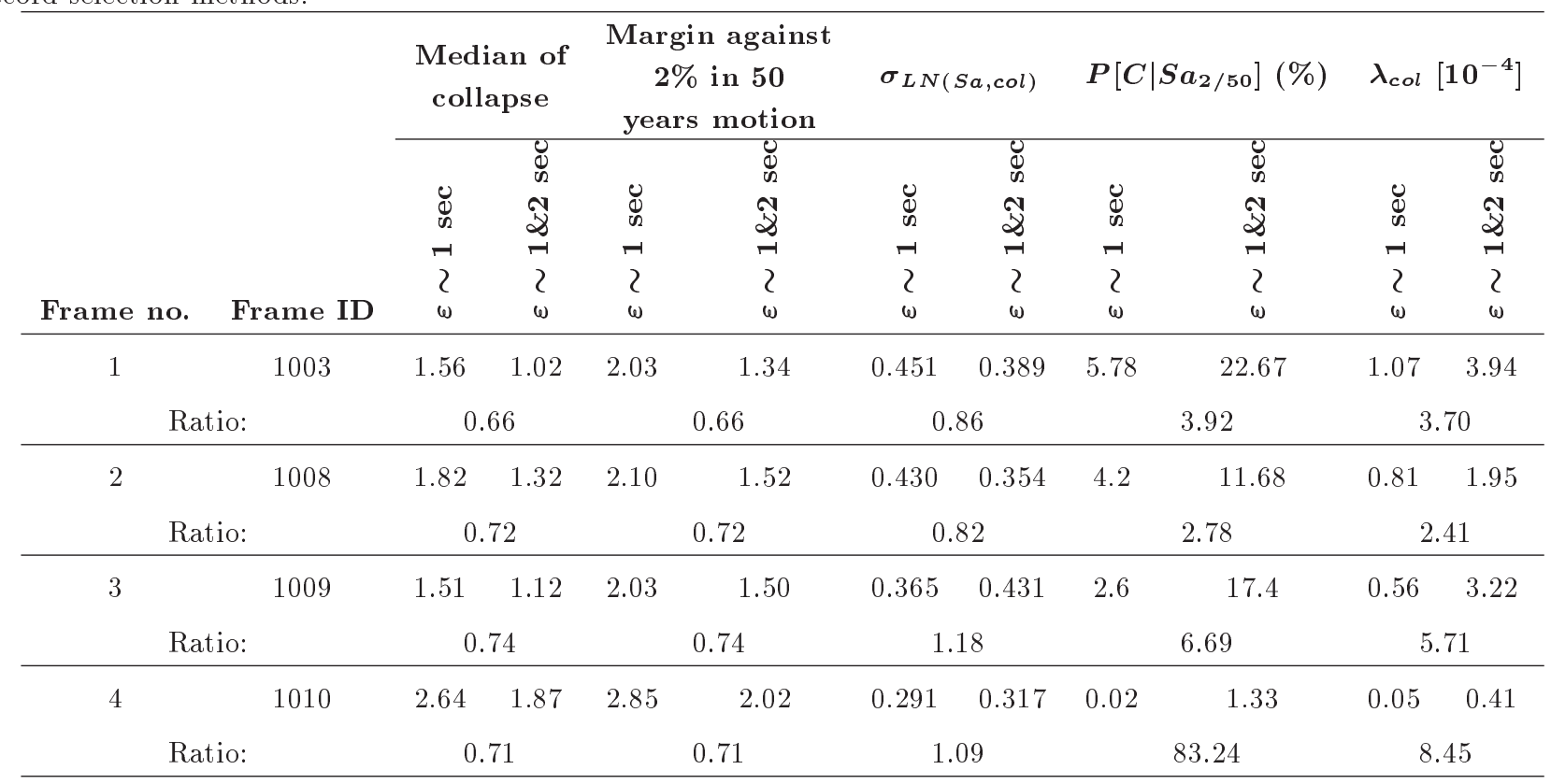

(conditioned on the ground motion intensity) with the ground motion hazard curve [52]. Therefore, the MAF of collapse is calculated at three hazard levels. Results show that the MAF of collapse obtained from the proposed approach can be up to 9 times larger than that obtained from common record selection methods. Moreover, the MAF of space frames is more sensitive to the ground motion records selected regarding the elongated period. All the aforementioned results are given in Tables $4-6$.

\section{Conclusion}

This research illustrated the importance of ground motion record selection in order to assess the seismic performance and collapse potential of reinforced concrete moment-resisting structures and focused mainly on the incorporation of the effect of period elongation on the ground motion intensity measure. A new approach was introduced for selecting ground motion records taking into account the effect of period elongation based on a vector-valued intensity measure regarding $S_{a}\left(T_{1}\right)$ and $\varepsilon$. The application of this method suggests selecting ground motion records by considering $\varepsilon$ at elongated (specifically, $2 T_{1}$ based on the proposition of Haselton and Baker [34]) and fundamental periods as well. Comparing the collapse capacity assessments for ground motion record sets selected with and without considering the effect of the period elongation showed up to a $45 \%$ decrease in the dispersion of the structural response. Furthermore, 0.7 times decrease in the median of collapse capacity was observed, suggesting that neglecting the effect of period elongation would make the structure more vulnerable to the earthquake 
Table 5. Collapse predictions for different design systems for $10 \%$ at a 50 -year hazard level including the results of both record selection methods.

\begin{tabular}{|c|c|c|c|c|c|c|c|c|c|c|c|}
\hline \multirow[b]{2}{*}{ Frame no. } & \multirow[b]{2}{*}{ Frame ID } & \multicolumn{2}{|c|}{$\begin{array}{c}\text { Median of } \\
\text { collapse }\end{array}$} & \multicolumn{2}{|c|}{$\begin{array}{c}\text { Margin against } \\
10 \% \text { in } 50 \\
\text { years motion }\end{array}$} & \multicolumn{2}{|c|}{$\sigma_{L N(S a, c o l)}$} & \multicolumn{2}{|c|}{$P\left[C \mid S a_{10 / 50}\right](\%)$} & \multicolumn{2}{|c|}{$\lambda_{c o l}\left[10^{-4}\right]$} \\
\hline & & $\begin{array}{l}0 \\
d \\
w \\
-1 \\
2 \\
\omega\end{array}$ & $\begin{array}{l}0 \\
0 \\
0 \\
N \\
2 \\
2 \\
-1 \\
2 \\
\omega\end{array}$ & $\begin{array}{l}0 \\
d \\
\omega \\
-1 \\
2 \\
\omega\end{array}$ & $\begin{array}{l}0 \\
d \\
w \\
N \\
2 \\
-1 \\
2 \\
\omega\end{array}$ & $\begin{array}{l}0 \\
\mathscr{U} \\
\tilde{2} \\
-1 \\
2 \\
\omega\end{array}$ & $\begin{array}{l}0 \\
0 \\
0 \\
w \\
1 \\
2 \\
7 \\
2 \\
w\end{array}$ & $\begin{array}{l}u \\
0 \\
\omega \\
-1 \\
2 \\
\omega\end{array}$ & $\begin{array}{l}0 \\
8 \\
w \\
N \\
2 \\
-1 \\
2 \\
\omega\end{array}$ & $\begin{array}{l}0 \\
d \\
w \\
-1 \\
2 \\
\omega\end{array}$ & $\begin{array}{l}0 \\
0 \\
w \\
2 \\
2 \\
2 \\
-1 \\
2 \\
\omega\end{array}$ \\
\hline 1 & 1003 & 1.44 & 1.05 & 2.80 & 2.04 & 0.442 & 0.448 & 0.99 & 5.51 & 1.37 & 4.90 \\
\hline \multicolumn{2}{|c|}{ Ratio: } & \multicolumn{2}{|c|}{0.73} & \multicolumn{2}{|c|}{0.73} & \multicolumn{2}{|c|}{1.01} & \multicolumn{2}{|c|}{5.57} & \multicolumn{2}{|c|}{3.58} \\
\hline 2 & 1008 & 2.04 & 1.41 & 3.48 & 2.41 & 0.313 & 0.384 & 0.00 & 1.11 & 0.19 & 1.77 \\
\hline \multicolumn{2}{|c|}{ Ratio: } & \multicolumn{2}{|c|}{0.69} & \multicolumn{2}{|c|}{0.69} & \multicolumn{2}{|c|}{1.23} & \multicolumn{2}{|c|}{ - } & \multicolumn{2}{|c|}{9.58} \\
\hline 3 & 1009 & 1.61 & 1.18 & 3.25 & 2.39 & 0.488 & 0.506 & 0.79 & 4.25 & 1.09 & 4.06 \\
\hline \multicolumn{2}{|c|}{ Ratio: } & \multicolumn{2}{|c|}{0.73} & \multicolumn{2}{|c|}{0.73} & \multicolumn{2}{|c|}{1.04} & \multicolumn{2}{|c|}{5.38} & \multicolumn{2}{|c|}{3.72} \\
\hline 4 & 1010 & 2.8 & 2.02 & 4.56 & 3.29 & 0.361 & 0.377 & 0.00 & 0.079 & 0.07 & 0.44 \\
\hline \multicolumn{2}{|c|}{ Ratio: } & \multicolumn{2}{|c|}{0.72} & \multicolumn{2}{|c|}{0.72} & \multicolumn{2}{|c|}{1.04} & \multicolumn{2}{|c|}{ - } & \multicolumn{2}{|c|}{6.31} \\
\hline
\end{tabular}

Table 6. Collapse predictions for different design systems for $20 \%$ at a 50 -year hazard level including results for both record selection methods.

\begin{tabular}{|c|c|c|c|c|c|c|c|c|c|c|c|}
\hline \multirow[b]{2}{*}{ Frame no. } & \multirow[b]{2}{*}{ Frame ID } & \multicolumn{2}{|c|}{$\begin{array}{c}\text { Median of } \\
\text { collapse }\end{array}$} & \multicolumn{2}{|c|}{$\begin{array}{c}\text { Margin against } \\
20 \% \text { in } 50 \\
\text { years motion }\end{array}$} & \multicolumn{2}{|c|}{$\sigma_{L N(S a, c o l)}$} & \multicolumn{2}{|c|}{$P\left[C \mid S a_{20 / 50}\right](\%)$} & \multicolumn{2}{|c|}{$\lambda_{\text {col }}\left[10^{-4}\right]$} \\
\hline & & $\begin{array}{l}u \\
0 \\
w \\
-1 \\
2 \\
\omega\end{array}$ & $\begin{array}{l}0 \\
0 \\
w \\
N \\
2 \\
-1 \\
2 \\
\omega\end{array}$ & $\begin{array}{l}u \\
d \\
w \\
-1 \\
2 \\
\omega\end{array}$ & $\begin{array}{l}0 \\
0 \\
\omega \\
N \\
y \\
-1 \\
2 \\
\omega\end{array}$ & $\begin{array}{l}0 \\
0 \\
0 \\
-1 \\
2 \\
\omega\end{array}$ & $\begin{array}{l}0 \\
0 \\
d \\
2 \\
1 \\
2 \\
2 \\
-1 \\
2 \\
w\end{array}$ & $\begin{array}{l}u \\
d \\
\omega \\
-1 \\
2 \\
\omega\end{array}$ & $\begin{array}{l}0 \\
0 \\
0 \\
0 \\
1 \\
2 \\
-1 \\
2 \\
w\end{array}$ & $\begin{array}{l}u \\
d \\
w \\
-1 \\
2 \\
\omega\end{array}$ & 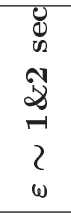 \\
\hline 1 & 1003 & 1.39 & 1.03 & 3.35 & 2.48 & 0.402 & 0.306 & 0.13 & 0.15 & 1.21 & 2.51 \\
\hline \multicolumn{2}{|c|}{ Ratio: } & \multicolumn{2}{|c|}{0.74} & \multicolumn{2}{|c|}{0.74} & \multicolumn{2}{|c|}{0.76} & \multicolumn{2}{|c|}{1.15} & \multicolumn{2}{|c|}{2.07} \\
\hline 2 & 1008 & 1.56 & 1.21 & 3.36 & 2.59 & 0.291 & 0.354 & 0.00 & 0.35 & 0.62 & 2.84 \\
\hline \multicolumn{2}{|c|}{ Ratio: } & \multicolumn{2}{|c|}{0.77} & \multicolumn{2}{|c|}{0.77} & \multicolumn{2}{|c|}{1.21} & \multicolumn{2}{|c|}{ - } & \multicolumn{2}{|c|}{4.58} \\
\hline 3 & 1009 & 1.5 & 1.08 & 3.70 & 2.66 & 0.411 & 0.335 & 0.07 & 0.17 & 0.83 & 2.11 \\
\hline \multicolumn{2}{|c|}{ Ratio: } & \multicolumn{2}{|c|}{0.72} & \multicolumn{2}{|c|}{0.72} & \multicolumn{2}{|c|}{0.81} & \multicolumn{2}{|c|}{2.35} & \multicolumn{2}{|c|}{2.55} \\
\hline 4 & 1010 & 2.22 & 1.79 & 4.39 & 3.54 & 0.336 & 0.374 & 0.00 & 0.04 & 0.20 & 0.77 \\
\hline \multicolumn{2}{|c|}{ Ratio: } & \multicolumn{2}{|c|}{0.81} & \multicolumn{2}{|c|}{0.81} & \multicolumn{2}{|c|}{1.11} & \multicolumn{2}{|c|}{ - } & \multicolumn{2}{|c|}{3.87} \\
\hline
\end{tabular}

hazard. It should be noted that the proposed method lessens the sensitivity of structural response to different hazard levels. Predictions of the Mean Annual Frequency (MAF) of collapse for ground motion record sets with and without the effect of period elongation showed that $\lambda_{\text {collapse }}$ was 2 to 9 times higher when using the proposed selection approach. The $\lambda_{\text {collapse }}$ value calculated by the introduced method demonstrated greater stability at different hazard levels. Since the results obtained using the presented approach were believed to be more accurate, predicting the struc- tural performance using this method resulted in better prediction of the total vulnerability of structures.

\section{References}

1. Araújo, M., Macedo, L., Marques, M., and Castro J.M. "Code-based record selection methods for seismic performance assessment of buildings", Earthquake Engineering and Structural Dynamics, 45, pp. 129-148 (2016).

2. Han, S.W. and Ha, S.J. "Assessment of ground motion 
selection criteria specified in current seismic provisions with an accurate selection algorithm", Bulletin of Earthquake Engineering, 15, pp. 4113-4132 (2017).

3. Macedo, L. and Castro, J.M. "SelEQ: An advanced ground motion record selection and scaling framework", Advances in Engineering Software, 114, pp. 32-47 (2017).

4. Ha, S.J. and Han, S.W. "An efficient method for selecting and scaling ground motions matching target response spectrum mean and variance", Earthquake Engineering and Structural Dynamics, 45, pp. 13811387 (2016).

5. Moschen, L., Medina, R.A., and Adam, C. "A ground motion record selection approach based on multiobjective optimization", Journal of Earthquake Engineering, 23(4), pp. 669-687 (2019).

6. Shahrouzi, M. and Sazjini, M. "Refined harmony search for optimal scaling and selection of accelerograms", Scientia Iranica, 19, pp. 218-224 (2012).

7. Dehghani, M. and Tremblay, R. "Robust periodindependent ground motion selection and scaling for effective seismic design and assessment", Journal of Earthquake Engineering, 20, pp. 185-218 (2016).

8. Yakhchalian, M., Ghodrati Amiri, G., and Eghbali, M. "Reliable seismic collapse assessment of short-period structures using new proxies for ground motion record selection", Scientia Iranica, 24, pp. 2283-2293 (2017).

9. Shome, N., Cornell, C.A., Bazzurro, P., and Carballo, J.E. "Earthquakes, records, and nonlinear responses", Earthquake Spectra, 14, pp. 469-500 (1998).

10. Baker, J.W. and Cornell, C.A. "A vector-valued ground motion intensity measure consisting of spectral acceleration and epsilon", Earthquake Engineering \& Structural Dynamics, 34, pp. 1193-1217 (2005).

11. Haselton, C.B., Baker, J.W., Liel, A.B., and Deierlein, G.G. "Accounting for ground-motion spectral shape characteristics in structural collapse assessment through an adjustment for epsilon", Journal of Structural Engineering, 137, pp. 332-344 (2011).

12. Luco, N. and Cornell, C.A. "Structure-specific scalar intensity measures for near-source and ordinary earthquake ground motions", Earthquake Spectra, 23(2), pp. 357-392 (2007).

13. Iwan, W. "Drift spectrum: measure of demand for earthquake ground motions", Journal of Structural Engineering, 123(4), pp. 397-404 (1997).

14. Baker, J.W. "Conditional mean spectrum: Tool for ground-motion selection", Journal of Structural Engineering, 137, pp. 322-331 (2010).

15. McGuire, R.K. "Probabilistic seismic hazard analysis and design earthquakes: closing the loop", Bulletin of the Seismological Society of America, 85, pp. 12751284 (1995).

16. Kazantzi, A.K. and Vamvatsikos, D. "Intensity measure selection for vulnerability studies of building classes", Earthquake Engineering \& Structural Dynamics, 44, pp. 2677-2694 (2015).
17. Kohrangi, M., Vamvatsikos, D., and Bazzurro, P. "Implications of IM selection for seismic loss assessment of 3D buildings", Earthquake Spectra, 32, pp. 2167-2189 (2016).

18. Kohrangi, M., Bazzurro, P., Vamvatsikos, D., and Spillatura, A. "Conditional spectrum-based ground motion selection using average spectral acceleration", Earthquake Engineering \& Structural Dynamics, 46, pp. 1667-1685 (2017).

19. Kohrangi, M., Bazzurro, P., and Vamvatsikos, D. "Vector and scalar IMs in structural response estimation: Part I - Hazard analysis", Earthquake Spectra, 32, pp. 1507-1524 (2016).

20. Kohrangi, M., Bazzurro, P., and Vamvatsikos, D. "Vector and scalar IMs in structural response estimation: Part II - Building demand assessment", Earthquake Spectra, 32, pp. 1525-1543 (2016).

21. Modica, A. and Stafford, P.J. "Vector fragility surfaces for reinforced concrete frames in Europe", Bulletin of Earthquake Engineering, 12, pp. 1725-1753 (2014).

22. Jayaram, N., Shome, N., and Rahnama, M. "Development of earthquake vulnerability functions for tall buildings", Earthquake Engineering \& Structural Dynamics, 41, pp. 1495-1514 (2012).

23. Trifunac, M., Ivanovic, S., and Todorovska, M. "Apparent periods of a building. II: Time-frequency analysis", Journal of Structural Engineering, 127, pp. 527537 (2001).

24. Clinton, J.F., Bradford, S.C., Heaton, T.H., and Favela, J. "The observed wander of the natural frequencies in a structure", Bulletin of the Seismological Society of America, 96, pp. 237-257 (2006).

25. Masi, A. and Vona, M. "Experimental and numerical evaluation of the fundamental period of undamaged and damaged RC framed buildings", Bulletin of Earthquake Engineering, 8, pp. 643-656 (2010).

26. Pinho, R. and Elnashai, A.S. "Dynamic collapse testing of a full-scale four storey RC frame", ISET Journal of Earthquake Technology, 37, pp. 143-163 (2000).

27. Jeong, S.H. and Elnashai, A.S. "Analytical assessment of an irregular RC frame for full-scale 3D Pseudodynamic testing Part I: Analytical model verification", Journal of Earthquake Engineering, 9, pp. 95-128 (2005).

28. Zembaty, Z., Kowalski, M., and Pospisil, S. "Dynamic identification of a reinforced concrete frame in progressive states of damage", Engineering Structures, 28, pp. 668-681 (2006).

29. Dunand, F., Guéguen, P., Bard, P., Rodgers, J., and Celebi, M. "Comparison of the dynamic parameters extracted from weak, moderate and strong building motion", in 1st European Conference of Earthquake Engineering and Seismology, Geneva, Switzerland (2006).

30. Michel, C. and Gueguen, P. "Time-frequency analysis of small frequency variations in civil engineering 
structures under weak and strong motions using a reassignment method", Structural Health Monitoring, 9, pp. 159-171 (2010).

31. Mucciarelli, M., Masi, A., Gallipoli, M.R., Harabaglia, P., Vona, M., Ponzo, F., and Dolce, M. "Analysis of RC building dynamic response and soil-building resonance based on data recorded during a damaging earthquake (Molise, Italy, 2002)", Bulletin of the Seismological Society of America, 94, pp. 1943-1953 (2004).

32. Calvi, G.M., Pinho, R., and Crowley, H. "State-of-theknowledge on the period elongation of RC buildings during strong ground shaking", First European Conference on Earthquake Engineering and Seismology, Geneva, Switzerland (2006).

33. Ergun, M. and Ates, S. "Selecting and scaling ground motion time histories according to Eurocode 8 and ASCE 7-05", Earthquakes and Structures, 5, pp. 129142 (2013).

34. Haselton, C. and Baker, J. "Ground motion intensity measures for collapse capacity prediction: Choice of optimal spectral period and effect of spectral shape", 8th National Conference on Earthquake Engineering, San Francisco, California (2006).

35. Baker, J.W. and Cornell, C.A. "Which spectral acceleration are you using?", Earthquake Spectra, 22, pp. 293-312 (2006).

36. Boore, D.M. "Equations for estimating horizontal response spectra and peak acceleration from western North American earthquakes: a summary of recent work", Seismological Research Letters, 76, pp. 368-369 (2005).

37. Haselton, C.B. "Assessing seismic collapse safety of modern reinforced concrete moment frame buildings", Department of Civil and Environmental Engineering, Stanford University, PhD Dissertation (2006).

38. Baker, J.W. and Cornell, C.A., Vector-Valued Ground Motion Intensity Measures for Probabilistic Seismic Demand Analysis, The John A. Blume Earthquake Engineering Center, Stanford University (2007).

39. Abrahamson, N. and Silva, W. "Empirical response spectral attenuation relations for shallow crustal earthquakes", Seismological Research Letters, 68, pp. 94127 (1997).

40. PEER, Strong Ground Motion Database. Available: http://peer.berkeley.edu/nga

41. ACI Committee, Building Code Requirements for Structural Concrete and Commentary (ACI 318M-05): An ACI Standard (2005).

42. Altoontash, A. "Simulation and damage models for performance assessment of reinforced concrete beamcolumn joints", Department of Civil and Environmental Engineering, Stanford University, PhD Dissertation (2004).

43. Ibarra, L.F. and Krawinkler, H., Global Collapse of Frame Structures Under Seismic Excitations, The John A. Blume Earthquake Engineering Center, Stanford University (2005).
44. OpenSees, Open System for Earthquake Engineering Simulation, Available: http://opensees.berkeley.edu/

45. Vamvatsikos, D. and Cornell, C.A. "Incremental dynamic analysis", Earthquake Engineering \& Structural Dynamics, 31, pp. 491-514 (2002).

46. Bazzurro, P. and Cornell, C.A. "Disaggregation of seismic hazard", Bulletin of the Seismological Society of America, 89, pp. 501-520 (1999).

47. USGS, PSHA Disaggregation, Available: https:// geohazards.usgs.gov/deaggint/2008/

48. FEMA-273: NEHRP Guidelines for the Seismic Rehabilitation of Buildings, Federal Emergency Management Agency (1997).

49. Jayaram, N., Baker, J.W., Okano, H., Ishida, H., McCann M.W., and Mihara, Y. "Correlation of response spectral values in Japanese ground motions", Earthquake and Structures, 2, pp. 357-376 (2011).

50. Haselton, C.B., Liel, A.B., Dean, B.S., Chou, J.H., and Deierlein, G.G. "Seismic collapse safety and behavior of modern reinforced concrete moment frame buildings", ASCE 2007 Structures Congress: New Horizons Better Practices, Long Beach, California (2007).

51. Zareian, F., Krawinkler, H., Ibarra, L., and Lignos, D. "Disaggregation of seismic hazard", The Structural Design of Tall and Special Buildings, 19, pp. 167-181 (2009).

52. Baker, J.W. and Cornell, C.A., Uncertainty Specification and Propagation for Loss Estimation Using FOSM Method, Pacific Earthquake Engineering Research Center, College of Engineering, University of California (2003).

\section{Biographies}

Saber Ale Saheb Fosoul is a PhD Candidate at McMaster University, Hamilton, Ontario, Canada. His research is focused on improving the seismic performance of existing highway bridges in different thermal conditions utilizing a novel seismic isolation system called Fiber Reinforced Elastomeric Isolator. He has received his BS and MS degrees from the University of Isfahan, Isfahan, Iran where he also served as a graduate research assistant conducting research on assessing the effect of uncertainties on the seismic performance of reinforced concrete moment-resisting frames. Before joining McMaster University, he served as a faculty member in Ragheb Isfahani Higher Education Institute offering civil and architectural engineering courses. In recent years, his research interests have mainly been focused on performance-based earthquake engineering, passive control of structures, ground motion selection, and structural reliability.

Hossein Tajmir Riahi is an Associate Professor of Civil Engineering at the University of Isfahan (UI), Isfahan, Iran. He received his BS, MS, and PhD in Civil 
Engineering from Sharif University of Technology. He is a member of the Earthquake Engineering Research Institute and Iranian Construction Engineers Organization. His research interests include a broad area of topics in Structural and Earthquake Engineering with a special focus on the design and performance of seismic resistant structures and passive control of structures. He regularly teaches Mechanics of Materials, Earthquake-Resistant Design of Structures, and Dynamics of Structures at the UI. He has published more than 30 journal papers and also a book. He was the Head of Civil Engineering Department at the UI.
Nima Hatami Aloughareh received his BS degree in Civil Engineering from Shahid Chamran University, Ahvaz, Iran. He received his MS degree in Structural Engineering from the University of Isfahan, Isfahan, Iran. His research interests are mainly focused on performance-based earthquake engineering and ground motion selection reliability. He has about 12 years of experience in construction projects and their management. He has worked in different companies such as Zagros International Constructing Company, National Iranian South Oil Company, and City Bank of Iran. 